\title{
Application of the TEWI Methodology to a Desiccant Cooling System Interacting with a Microcogenerator
}

\author{
Giovanni Angrisani", Filippo de Rossi, Carlo Roselli and Maurizio Sasso
}

DING, Department of Engineering, University of Sannio, Piazza Roma 21, 82100 Benevento, Italy

\begin{abstract}
Desiccant cooling systems, supplied by fossil or renewable fuels, represent a very interesting alternative to conventional electric units based on cooling dehumidification for air conditioning purposes, as they can achieve significant energy and emissions savings. The analysis of environmental impact of energy conversion devices, e.g. in terms of global warming effect, is usually limited to energy-related emissions (indirect contribution), neglecting direct greenhouse gas emissions related to working fluids, such as refrigerants. The Total Equivalent Warming Impact (TEWI) is a more comprehensive methodology, as it takes into account both direct and an indirect contributions to global warming. In this paper, this method is applied to a small scale trigeneration system, in which a microcogenerator, a chiller and a boiler interact with a hybrid desiccant-based cooling system, equipped with a silica-gel desiccant wheel. This trigeneration system is compared with other two systems, in order to assess its potentiality in terms of TEWI reduction. The different direct and indirect contributions of the several equipment are evaluated, and the share of the direct contribution is investigated, considering both the overall TEWI of the complete system, and that of the electric vapour compression device only. Finally, the effect of the greenhouse gas emissions of the electricity production mix and of different values of the Global Warming Potential (GWP) of the refrigerant fluid on the overall TEWI of the three compared systems is investigated.
\end{abstract}

Keywords: Total equivalent warming impact, desiccant cooling system, microcogenerator, electricity production mix, global warming potential.

\section{INTRODUCTION}

Electrically-driven vapour compression devices represent the most diffused technology for airconditioning purposes during summer in residential and tertiary sectors; this is determining high electric peak loads and black-outs events. Due to this, an increasing interest towards gas cooling systems is occurring, as they shift summer energy demand from electricity to gas, and they allow to reduce the natural gas surplus during summer, due to the reduction of thermal energy requirements for space heating and domestic hot water purposes in this period.

Desiccant cooling systems (DCS), integrated with microcogenerators supplied by fossil or renewable fuels, represent a very interesting alternative to conventional units based on cooling dehumidification by means of electric chillers, as they can achieve significant energy and environmental impact savings. These potential savings can have a strategic role in the regulatory framework for energy consumption of buildings given by the $E U$ in order to reduce greenhouse gas (GHG) emissions and global temperature rise. To this regard, EU required Member States to implement in the next future nearly Net Zero Energy Buildings regulations, to which hybrid desiccant cooling systems can significantly contribute, [1].

*Address correspondence to this author at the DING, Department of Engineering, University of Sannio, Piazza Roma 21, 82100 Benevento, Italy; Tel: +39-0824305576; Fax: +39-0824325246;

E-mail: giovanni.angrisani@unisannio.it
The environmental impact of energy systems in terms of GHG emissions is usually evaluated considering only their energy consumption, [2], neglecting the emissions related to the working fluids of energy conversion devices.

For example, as regards DCS, in [3], a solar DCS for an institutional building in subtropical Australia was assessed using TRNSYS 16 software. The technical performance, economic analysis, energy savings and avoided gas emissions were quantified with reference to a conventional heating ventilation and air conditioning (HVAC) system under the influence of typical meteorological year of the installation site. Namely, the technical parameter used to assess the environmental viability is the avoided $\mathrm{CO}_{2}$ emissions, calculated by the product of saved electricity and the related emission factor. Results showed that the installed cooling system, which consisted of $10 \mathrm{~m}^{2}$ of solar collectors, achieved annual avoided gas emissions of about 4.4 tonnes of $\mathrm{CO}_{2}$.

In [4], a desiccant-based air handling unit (AHU) with desiccant wheel (DW) and novel concentrating photovoltaic/thermal collectors were coupled. A TRNSYS project based on models available in literature was developed. Electricity produced by collectors is used to power the auxiliaries of the AHU, the chiller and also to meet the electric load of the users, while thermal energy is used to heat the regeneration air flow during summer and the process 
air in winter. Excess electricity is sold to the grid, whereas surplus thermal energy is used for domestic hot water (DHW) production. Energy and environmental performance of the overall system in terms of primary energy saving and emission reduction with respect to a reference case were evaluated. Emissions were calculated considering electricity and natural gas consumption, and their emission factors. The avoided equivalent $\mathrm{CO}_{2}$ emissions of the investigated system was in the range $85 \%-91 \%$, depending on the DHW usage.

In [5], a gas-fired desiccant cooling system installed in a wet market in Hong Kong was investigated by insitu measurements, site surveys and simulations. The verified computer model was used for further simulations. It was found that with a minimum ventilation rate of $10.3 \mathrm{~L} /(\mathrm{s} \cdot$ person), the use of desiccant cooling system as compared to conventional one saved $4 \%$ of the energy, achieving the desired space conditions. A parametric study under various ventilation rates indicated that use of desiccant cooling system in wet markets in hot and humid Hong Kong would lead to energy and energy cost savings, as well as $\mathrm{CO}_{2}$ emission reductions up to $13 \%$. The environmental impact was assessed on the basis of emission factor of electricity generation in Hong Kong and of natural gas.

In [6], a small scale polygeneration system based on a natural gas-fired MCHP (Micro Combined Heat and Power) and a desiccant HVAC system, located in Southern Italy, was analyzed by means of experiments. The MCHP provides thermal power, recovered from engine cooling and exhaust gas, for the regeneration of the DW and electric power for the chiller, the auxiliaries and electric devices such as computers, lights, etc. The HVAC system can also operate in traditional way, by interacting with electric grid and gas-fired boiler. An overview of the main experimental results was shown, considering both the desiccant wheel and the global polygeneration system. The latter guaranteed primary energy savings up to $21.2 \%$ and greenhouse-gas emissions reductions up to $38.6 \%$ with respect to conventional HVAC systems based on separate energy "production". Equivalent carbon dioxide emissions deriving from energy consumption were calculated.

The paper in [7], using the same test facility of [6], identified the operating conditions (outdoor and supply air thermal-hygrometric conditions, electric grid efficiency and partial load operation of the MCHP) which guarantee significant primary energy savings (up to around $30 \%$ ) and $\mathrm{CO}_{2}$ equivalent emission reductions (up to around $40 \%$ ) of the polygeneration system compared to the conventional HVAC system.

In [8], the same small scale trigeneration system investigated in $[6,7]$, in which a heat-led microcogenerator interacts with a desiccant-based cooling system, equipped with a silica-gel DW, was analyzed. The system provided the air-conditioning service to a lecture room during summer and winter periods and, over the whole year, thermal energy for DHW production to a nearby multifamily house. This trigeneration system was compared with a reference system, equipped with a conventional air handling unit, based on cooling dehumidification for summer air conditioning. Experimental tests and data derived from manufacturers were used to implement a model of both systems. Simulations were then performed by means of TRNSYS software to compare their thermoeconomic performance. The analysis showed encouraging results, in terms of primary energy consumption and equivalent $\mathrm{CO}_{2}$ emissions reductions, with maximum values of $7.70 \%$ and $15.3 \%$, respectively.

In [9], experimental tests and data derived from scientific and technical literature were used to implement a model of a solar DCS, considering three different collector technologies (air, flat-plate and evacuated collectors). Simulations were then performed to compare the energy, environmental and economic performance of the system with those of a desiccant-based unit where regeneration thermal energy is supplied by a natural gas boiler, and with those of a conventional air-handling unit. The only solution that achieved the economic feasibility of the solar desiccant cooling unit consists of $16 \mathrm{~m}^{2}$ of evacuated solar collectors. This is able to obtain, with respect to the conventional system, a reduction of primary energy consumption and equivalent $\mathrm{CO}_{2}$ emissions of about $50 \%$, but with a payback time of 20 years.

In [10], experimental tests to investigate a hybrid DCS with DW, interacting with a small scale cogenerator, were used. The performance were analyzed varying several operating conditions, namely regeneration temperature, rotational speed, volume air flow rates, outdoor air temperature and humidity ratio. Several performance parameters, based on electric, thermal and primary energy, were investigated. Furthermore, the hybrid DCS with microcogenerator was compared with other thermal or electrical air- 
conditioning technologies. The comparison about environmental impact was performed in terms of equivalent $\mathrm{CO}_{2}$ emissions deriving from energy consumption. The results showed that the investigated DCS performs better or at least equal than the other thermally-activated systems, while the result of the comparison with the conventional electric unit depends on the outdoor air conditions.

In the reviewed literature, as previously stated, only energy consumption related emissions are taken into account. A more comprehensive analysis can be performed by means of the TEWI (Total Equivalent Warming Impact) index, that is commonly used in the ecological evaluation of vapour compression refrigerating plants, $[11,12]$, as they provide both direct and indirect contributions to global warming. The former depends on the GWP (Global Warming Potential) of refrigerant fluids and on the amount of refrigerant charge wasted in the surrounding environment during operation and maintenance and at the end of the technical life of the unit. GWP is a relative measure of the greenhouse effect of a certain gas in the atmosphere. It compares the effect of that gas to that of an equal mass of carbon dioxide, whose GWP is set to 1. GWP is calculated over a specific integration time, commonly 20,100 or 500 years. The indirect contribution is related to the energy consumption of the system, either electricity or fossil fuels. This contribution is more complex to be evaluated, as it depends on several factors, such as the performance factor of the system (e.g. the COP), the efficiency of the electricity production mix (in case of electric-driven devices), the fuel used, etc. The literature provides some indicative values of $\mathrm{CO}_{2}$ emissions per kWh of electricity for each country, and of $\mathrm{CO}_{2}$ emissions per $\mathrm{kWh}$ of primary energy for each fossil fuel.

As an example, in [13] a desiccant dehumidification system driven by low grade $\left(<80^{\circ} \mathrm{C}\right)$ waste heat was investigated on the basis of experimental data. The air flow at the outlet of the gas cooler of a trans-critical cycle is forced through a desiccant wheel for regeneration purposes. The hybrid trans-critical refrigerator-desiccant system improved COP by approximately $77 \%$ as compared to a classical transcritical. The economic analysis suggested that the investment return-time is acceptable (lower than about 8 years) only at ambient temperature exceeding $35^{\circ} \mathrm{C}$. The ecological analysis indicated that the TEWI of the classical trans-critical cycle exceeds that of the hybrid system, by approximately $60 \%$.
To the authors' knowledge, there are no papers where TEWI methodology is applied to assess the overall environmental impact of plants consisting of several energy conversion devices. In this work, the TEWI method is applied to a system consisting of a small scale trigeneration unit, in which a heat-led microcogenerator, a boiler and a chiller interact with a hybrid DCS, equipped with a silica-gel desiccant wheel. The system provides the air-conditioning service to a lecture room during summer and winter periods, and thermal energy for DHW production, over the whole year, to a nearby multifamily house (MFH). More generally, hot water from the MCHP could be provided to a thermal user (a sports center, a pool, a leisure complex, etc.) in the premises of the lecture room.

This trigeneration system is compared with two systems, the former has the same hybrid DCS, while the latter is equipped with a conventional air handling unit, based on cooling dehumidification for summer air conditioning. In both systems, electricity is drawn from the grid and thermal energy is provided by a natural gas boiler, instead of by the MCHP. Starting from the results achieved in [8], the TEWI is calculated for the three systems, considering the contributions of each device as well as different electricity mix scenarios.

\section{THE USERS}

The microtrigeneration system is installed in Benevento (Southern Italy), that belongs to Italian climatic zone C, with 1316 heating degree days and a heating period lasting from November 15th to March 31 st. The summer activation period of the air conditioning service for the lecture room was assumed from June 1st to September 15th.

The lecture room has a floor area of $63.5 \mathrm{~m}^{2}$, activation schedule of the air-conditioning service from Monday to Saturday from 8:30 to 19:00 during both summer and winter periods. The summer and winter set-point temperatures are $26{ }^{\circ} \mathrm{C}$ and $20{ }^{\circ} \mathrm{C}$, respectively, and the relative humidity set-point is $50 \%$ in both periods. The lecture room has 30 seats and is occupied from Monday to Saturday. The maximum sensible thermal load is $36 \mathrm{~kW}$, while the maximum sensible cooling load is about $16 \mathrm{~kW}$. The sensible and latent energy loads are $2.38 \mathrm{MWh} / \mathrm{y}$ and $1.04 \mathrm{MWh} / \mathrm{y}$, respectively, during summer, and $5.11 \mathrm{MWh} / \mathrm{y}$ and 0.78 $\mathrm{MWh} / \mathrm{y}$, respectively, during winter. The electricity requirement is $139 \mathrm{kWh} /\left(\mathrm{m}^{2} \cdot \mathrm{y}\right)$.

As regards hot water demands of the MFH or the generic thermal user (a sports center, a pool, a leisure 




Figure 1: The layout of System I during summer operation.

complex, etc.), a requirement of 1,200 L/day was set. A hot water supply temperature of $45^{\circ} \mathrm{C}$ was assumed, with an energy demand of $18.2 \mathrm{MWh} / \mathrm{y}$.

\section{DESCRIPTION OF COMPARED SYSTEMS}

\subsection{System I}

The main components of the hybrid system are (Figure 1):

- $\quad$ an $\mathrm{AHU}$ equipped with a DW,

- an MCHP, based on a natural gas fuelled reciprocating internal combustion engine. It has a nominal thermal power output of $11.7 \mathrm{~kW}$, a net electric power output of $5.6 \mathrm{~kW}$ and a primary fuel requirement of $20.8 \mathrm{~kW}$. Rated net electric and thermal efficiency are $26.9 \%$ and $56.3 \%$, respectively;

- $\quad$ an electric air-cooled water chiller, with a rated cooling capacity and a nominal EER (Energy Efficiency Ratio) of $8.50 \mathrm{~kW}$ and 2.98, respectively;

- a natural gas boiler, with a rated thermal power of $24.1 \mathrm{~kW}$ and a nominal thermal efficiency of $90.2 \%$;

- a thermal storage (TS), made of carbon steel, with a net storage volume of $855 \mathrm{~L}$.
As regards the $\mathrm{AHU}$, it handles three air flows, with a nominal flow rate of $800 \mathrm{~m}^{3} / \mathrm{h}$. The DW is filled with silica gel, a desiccant material that can be regenerated at temperatures as low as $60-70^{\circ} \mathrm{C}$. It has a diameter of $700 \mathrm{~mm}$ and a thickness of $200 \mathrm{~mm}$. Sixty percent of the rotor area is used for process air, while the remaining $40 \%$ for the regeneration air. The pumps of the boiler, the chiller and the MCHP have an electric requirement of $150 \mathrm{~W}$ each, while the process, regeneration and cooling air fans require $320 \mathrm{~W}$ each.

During summer period, the cooling mode is active: the three air flows are entirely drawn from the outdoor (state 1 in Figure 1). The process air is dehumidified by the desiccant wheel (1-2), pre-cooled by the cooling air stream in an air-to-air cross flow heat exchanger (CF), $2-3$, and finally cooled to the supply temperature by a cooling coil $(\mathrm{CC})$ interacting with the chiller $(\mathrm{CH}), 3-4$. The regeneration air is heated by the heating coil $(\mathrm{HC})$ interacting with the TS and/or the boiler (B), 1-5, in order to regenerate the desiccant material (5-6). The cooling air is cooled by an evaporative cooler (EC), 17 , and then used to pre-cool the process air (7-8).

Thermal energy stored is used to regenerate the DW: the HC in the process air duct is fed by the hot water from the TS, in which thermal energy is supplied by the heat-led MCHP. The required regeneration temperature depends on the desired humidity ratio reduction of moist air and on other operating 


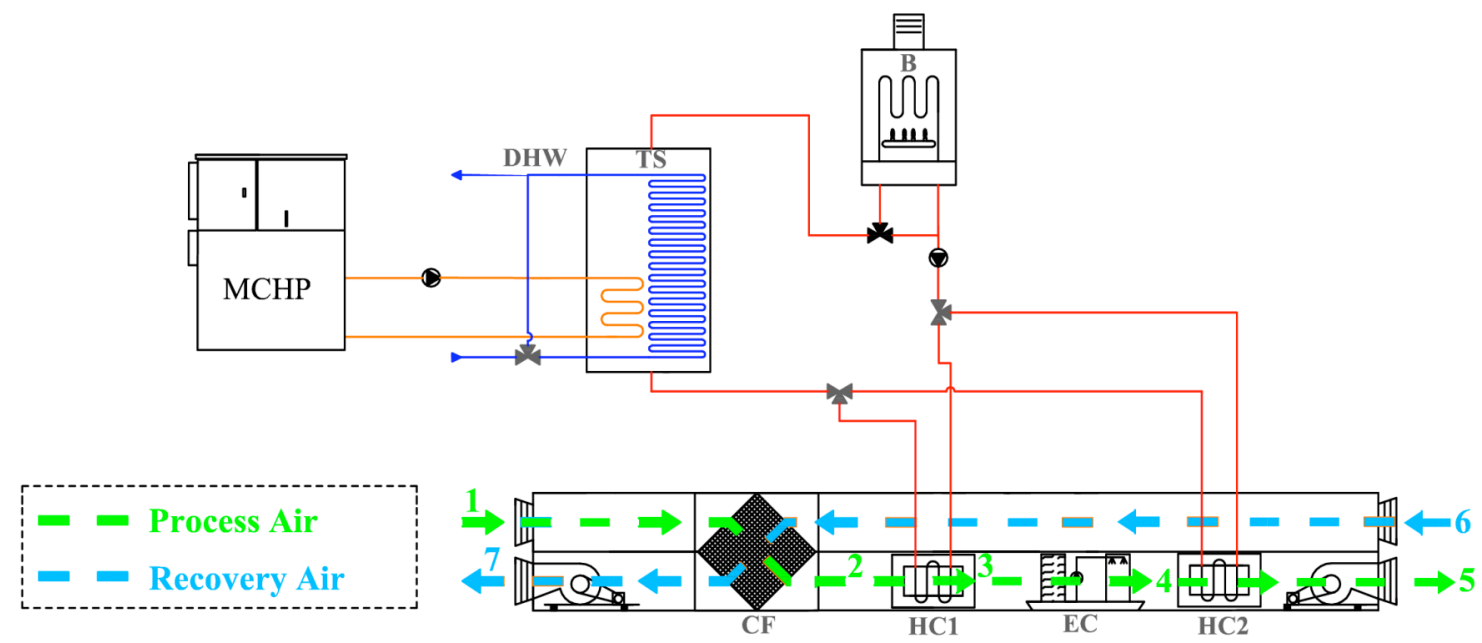

Figure 2: The layout of System I during winter operation.

parameters (e.g., inlet temperature and humidity ratio of process air). If thermal energy from TS is not enough to heat the regeneration air up to the required temperature, the boiler heats the hot water coming from the tank up to the required temperature level (Figure 1).

In summer, 3 pumps and 3 fans are active in the AHU, with a total electric requirements of auxiliaries equal to $1,410 \mathrm{~W}$.

During winter operation, the AHU of Figure 1 is modified as follows (Figure 2):

- $\quad$ only two ducts are used, for the process air and the recovery one respectively (nominal flow rate $800 \mathrm{~m}^{3} / \mathrm{h}$ ), the latter coming from the indoor (state 6 in Figure 2);

- $\quad$ the DW is not used;

- the CF heat exchanger is used to transfer heat from the recovery air (6-7) to the process air (12), for pre-heating purposes;

- the first coil (2-3) in the process air duct (that was a cooling coil during summer period) is supplied with hot water from the TS and/or the boiler;

- $\quad$ an evaporative cooler (3-4) and an additional heating coil (4-5), fed with hot water from the TS and/or the boiler, are added in the process air duct.

When the temperature of the water coming from the TS is lower than that required for the pre and postheating processes, the auxiliary boiler is switched on.
In winter, 2 pumps and 2 fans are active, with a total electric requirements of auxiliaries equal to $940 \mathrm{~W}$.

When the AHU is switched off, thermal energy requirements are related to DHW demand only and electricity is used to activate the MCHP pump (150 W) and the electric devices of the lecture room (lighting, personal computers, etc.) It is assumed, as an hypothesis, that $50 \%$ of the annual electricity demand of the AHU and lecture room is supplied by the MCHP, and the remaining amount is taken from the external grid; the surplus electricity from the MCHP is fed to the grid. This is only an hypothesis for calculation purposes, and it does not affect the final results in terms of TEWI, as in this paper the same specific emission factor is assumed for electricity drawn and fed to the grid.

For DHW production, cold water coming from the mains is heated in the TS and supplied to the thermal user at $45^{\circ} \mathrm{C}$. If the water in the storage is hotter than $45{ }^{\circ} \mathrm{C}$, a three-way valve mixes the water that bypasses the TS with the hot fluid exiting the storage, to reach the desired temperature of $45{ }^{\circ} \mathrm{C}$. If the temperature of DHW at the outlet of the tank is lower than $45^{\circ} \mathrm{C}$, an on-site boiler, installed in the premises of the thermal user, provides for the shortage. This boiler is not accounted for in the energy and environmental analysis, as it is outside the control volume to which the energy balances are referred.

In all operating modes (cooling, heating and DHW only), the MCHP system is heat-led, i.e. it operates according to a temperature signal coming from a sensor placed in the TS close to the inlet port of the internal heat exchanger: when the temperature reduces below $58{ }^{\circ} \mathrm{C}$ (due to thermal energy requirements for 




Figure 3: The layout of System II during summer operation.

regeneration, space heating or $\mathrm{DHW}$ ), the unit is activated; when it is higher than $60{ }^{\circ} \mathrm{C}$, the unit is turned off. In the heat-lead operation, the MCHP runs at nominal thermal and net electric power, therefore the related efficiency values are very close to the respective rated values.

\subsection{System II}

This system has the same AHU layout of system I, both in summer (Figure 1) and winter (Figure 2), but thermal power for regeneration of the wheel, for space heating purposes and for DHW demand is supplied by a natural gas-fired boiler (with the same thermal efficiency of the boiler in system I), while electricity for chiller, auxiliaries and electric devices is completely drawn from the electric grid. In Figures 3 and $\mathbf{4}$, the layout of the system for summer and winter operation is shown, respectively. In summer, 2 pumps and 3 fans are active, with a total electric requirements of auxiliaries equal to $1,260 \mathrm{~W}$; in winter, 1 pumps and 2 fans are active, with a total electric requirements of auxiliaries equal to $790 \mathrm{~W}$.

\subsection{System III (Reference Syetem)}

The reference system (RS) has to ensure the same air-conditioning service, electricity demand and DHW production provided by Systems I and II. For summer air conditioning purposes, the RS is equipped with a standard configuration of the AHU, in which only one air flow is used (process air), that is dehumidified by

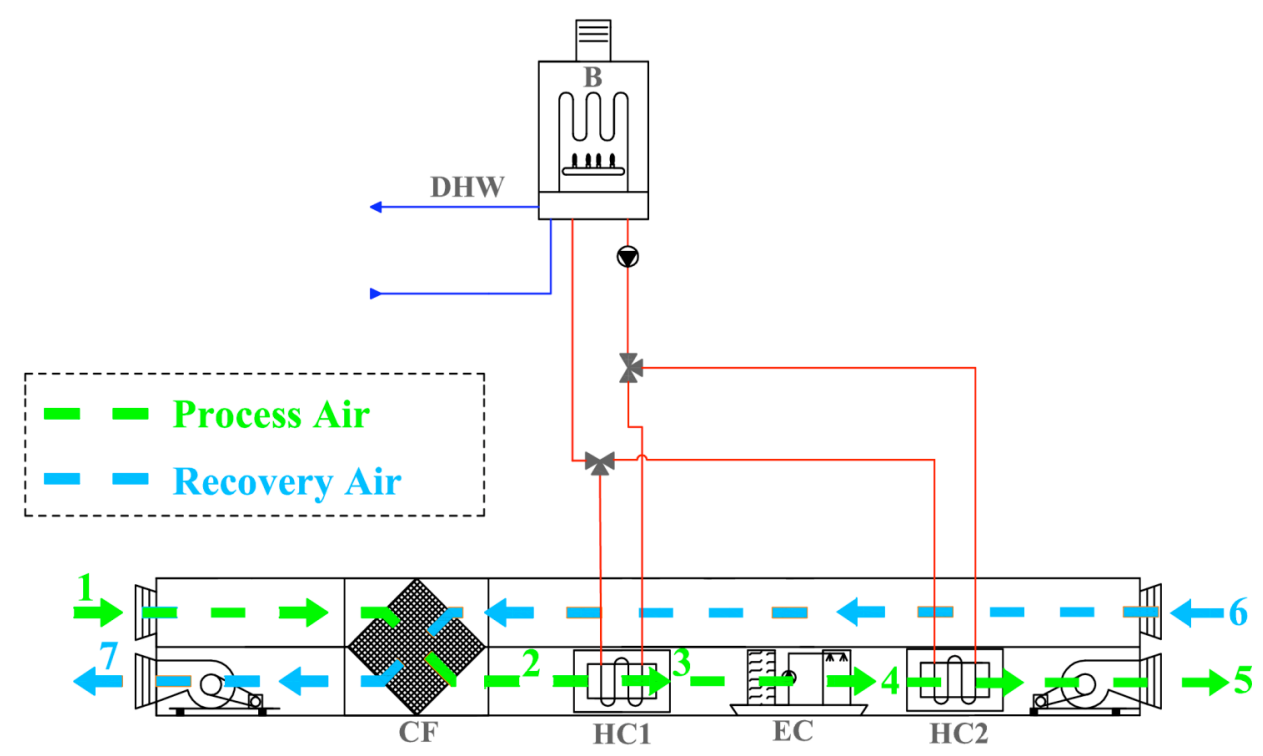

Figure 4: The layout of System II during winter operation. 


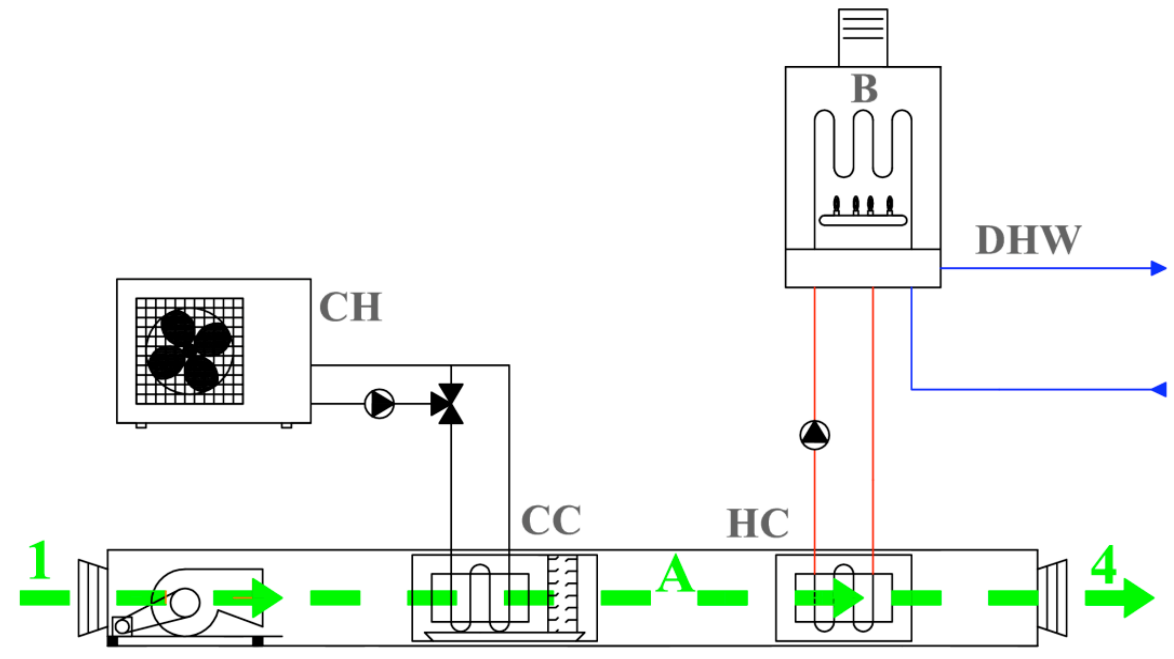

Figure 5: The layout of System III during summer operation.

means of a cooling coil connected to an electric chiller (process 1-A in Figure 5). Then it is post-heated to the supply temperature (process A-4 in Figure 5), before being introduced in the conditioned lecture room (state 4 in Figure 5, that has the same thermal-hygrometric properties of state 4 in Figure 1 and Figure 3 ).

The chiller in the reference system has to balance both the sensible and latent loads of process air, thus it operates with lower chilled water temperatures than the chiller in system I and II, that has to manage the sensible load only. Therefore, the chiller in System III has a higher rated capacity $(16.3 \mathrm{~kW})$, and a lower rated EER (2.72) than the one in system I and II, [14].

A conventional boiler is used to provide thermal energy to the system (both for post-heating and DHW), while electrical energy to activate the devices of the lecture room, the chiller and the auxiliaries of the AHU is taken from the grid.

In summer, 2 pumps and 1 fan are active, with a total electric requirements of auxiliaries equal to $620 \mathrm{~W}$.

The AHU of the reference system in the winter season has the same configuration than System II (Figure 4), where the heating coils for pre and postheating are fed by the boiler only, that provides thermal energy for DHW too. In this case, 1 pump and 2 fans are active, and the auxiliaries power consumption is $790 \mathrm{~W}$.

Finally, also for the RS, when the AHU is switched off, thermal energy requirements are related to DHW demand only. The thermal efficiency of the boiler is $90.2 \%$ in this system too.

\section{METHODOLOGY FOR ENVIRONMENTAL ASSESSMENT CRITERIA}

For system I, the TEWI parameter is calculated according to the following eq. 1 :

$T E W I_{1}=T E W I_{d i r}^{c h}+T E W I_{i n d}^{M C H P}+T E W I_{i n d}^{G B}+T E W I_{\text {ind }}^{E l}$

where $T E W I_{d i r}^{c h}$ is the direct contribution related to the refrigerant fluid (R407C) of the chiller, TEWI Ind ${ }_{\text {ind }}$ and $T E W I_{i n d}^{G B}$ are the indirect contributions related to natural gas consumption of the MCHP and the boiler, respectively, and $T E W I_{\text {ind }}^{E l}$ is the indirect contribution related to electricity exchange with the grid.

For systems II and III, where the MCHP is not installed, the $T E W I$ is given by:

$T E W I_{11 / 111}=T E W I_{d i r}^{c h}+T E W I_{i n d}^{G B}+T E W I_{\text {ind }}^{E l}$

The direct contribution of the chiller can be calculated as:

$T E W I_{d i r}^{c h}=R C\left[P_{L}+\left(1-P_{R}\right) / V\right] V \cdot G W P_{100}^{R 407 C}$

where $G W P_{100}^{R 407 C}$ is the Global Warming Potential of R407C over an integration time of 100 years.

The indirect contributions of MCHP and boiler can be evaluated, respectively, by:

$$
\begin{aligned}
& T E W I_{\text {ind }}^{M C H P}=P E_{\text {Fuel }}^{M C H P} \cdot \beta \cdot V \\
& T E W I_{\text {ind }}^{G B}=P E_{\text {Fuel }}^{G B} \cdot \beta \cdot V
\end{aligned}
$$

where $P E_{\text {Fuel }}^{M C H P}$ and $P E_{\text {Fuel }}^{G B}$ are the annual primary energy consumptions of the MCHP and the boiler, respectively. 
Table 1: Parameters for TEWI Calculations

\begin{tabular}{|c|c|c|}
\hline Symbol & Value & Units \\
\hline \hline RC for systems I and II & $2.5[14]$ & $\mathrm{kg}$ \\
\hline $\mathrm{RC}$ for system III & $3.0[14]$ & $\mathrm{kg}$ \\
\hline $\mathrm{P}_{\mathrm{L}}$ & $0.05[15]$ & (\% refrigerant charge/year) \\
\hline $\mathrm{P}_{\mathrm{R}}$ & $0.95[15]$ & years refrigerant charge) \\
\hline $\mathrm{V}$ & 20 & $\mathrm{~kg}_{\mathrm{CO} 2} / \mathrm{kg}_{\mathrm{GHG}}$ \\
\hline $\mathrm{GWP}_{100}^{\mathrm{R} 407 \mathrm{C}}$ & $1,525[16]-1,800[17]$ & $\mathrm{kg}_{\mathrm{CO} 2} / \mathrm{kWh}_{\mathrm{PE}}$ \\
\hline$\beta$ & $0.207[8]$ & $\mathrm{kg}_{\mathrm{CO} 2} / \mathrm{kWh}_{\mathrm{EI}}$ \\
\hline$\alpha$ & $0.573[8]$ & \\
\hline
\end{tabular}

As regards the indirect contribution of the electric grid, it can be evaluated as:

$$
T E W I_{i n d}^{E l}=\alpha \cdot V \cdot\left(D E^{E l}-X E^{E l}\right)
$$

where $D E^{E l}$ is the annual electricity drawn from the grid and $X E^{E l}$ is the annual electricity exported to the grid, that is zero for systems II and III.

As regards the parameters in Eqs. 3 to 6, the values listed in Table 1 were used. GWP values are subject to rather wide levels of uncertainty, in fact different values for the same fluid were found in literature. Therefore, in this paper the analysis will be carried out considering the minimum and maximum found values for the considered refrigerant fluid. As regards $\alpha$, the value reported in Table 1 refers to the Italian mix of thermoelectric power plant, including transmission and distribution losses but excluding renewable electricity.

The following comparison indices are defined:

$$
\Delta T E W I_{I-I I}=\left(T E W I_{I I}-T E W I_{I}\right) / T E W I_{I I}
$$

$\Delta T E W I_{I I-I I I}=\left(T E W I_{I I I}-T E W I_{I I}\right) / T E W I_{I I I}$

where $T E W I_{l}, T E W I_{\|}$and $T E W I_{\| I}$ are the Total Equivalent Warming Impact of system I, II and III, respectively.

\section{RESULTS}

In this section, the three systems are firstly compared by means of an energy analysis. Detailed models of the energy conversion devices and AHU components, as well as a deep description of simulation results can be found in [8].

Annual energy production of the energy conversion devices of system I (MCHP and boiler), as well as electric (chiller, auxiliaries and electric devices) and thermal energy requirements (DW regeneration, winter space heating and DHW) are reported in Table 2. The difference between thermal energy production and consumption (about $2.50 \mathrm{MW} \mathrm{h/y}$, that is $7.8 \%$ of the production) is the energy losses of the TS. Energy outputs of the microcogenerator determine a thermal efficiency of $55.6 \%$, an electric efficiency of $26.5 \%$ and

\begin{tabular}{|c|c|c|c|c|c|c|c|c|c|c|}
\hline & & MCHP & Boiler & Chiller & Auxiliaries & Electric devices & DW regeneration & Space heating & DHW & Total \\
\hline $\begin{array}{c}\text { Primary energy } \\
\text { consumption }\left(P E_{\text {Fuel }}\right)\end{array}$ & $\mathrm{MWh} / \mathrm{y}$ & 54.0 & 2.17 & - & - & - & - & - & - & 56.2 \\
\hline $\begin{array}{c}\text { Thermal energy } \\
\text { production }\end{array}$ & $\mathrm{MWh} / \mathrm{y}$ & 30.0 & 1.96 & - & - & - & - & - & - & 32.0 \\
\hline $\begin{array}{c}\text { Thermal energy } \\
\text { consumption }\end{array}$ & $\mathrm{MWh} / \mathrm{y}$ & - & - & - & - & - & 6.95 & 6.51 & 16.0 & 29.5 \\
\hline $\begin{array}{l}\text { Net electricity } \\
\text { production }\end{array}$ & $\mathrm{MWh} / \mathrm{y}$ & 14.3 & - & - & - & - & - & - & - & 14.3 \\
\hline $\begin{array}{c}\text { Electricity } \\
\text { fed to the grid }\left(X E^{E \prime}\right)\end{array}$ & $\mathrm{MWh} / \mathrm{y}$ & 7.90 & - & - & - & - & - & - & - & 7.90 \\
\hline $\begin{array}{c}\text { Electricity } \\
\text { Consumption }\left(N E^{E l}\right)\end{array}$ & $\mathrm{MWh} / \mathrm{y}$ & - & - & 1.40 & 2.58 & 8.83 & - & - & - & 12.8 \\
\hline
\end{tabular}

Table 2: Energy Analysis of System I 
Table 3: Energy Analysis of System II

\begin{tabular}{|c|c|c|c|c|c|c|c|c|c|}
\hline & & Boiler & Chiller & Auxiliaries & Electric devices & DW regeneration & Space heating & DHW & Total \\
\hline $\begin{array}{c}\text { Primary energy } \\
\text { consumption }\left(P E_{F u e l}\right)\end{array}$ & $\mathrm{MWh} / \mathrm{y}$ & 32.7 & - & - & - & - & - & - & 32.7 \\
\hline $\begin{array}{c}\text { Thermal energy } \\
\text { production }\end{array}$ & MWh/y & 29.5 & - & - & - & - & - & - & 29.5 \\
\hline $\begin{array}{l}\text { Thermal energy } \\
\text { consumption }\end{array}$ & MWh/y & - & - & - & - & 6.95 & 6.51 & 16.0 & 29.5 \\
\hline $\begin{array}{c}\text { Electricity } \\
\text { Consumption }\left(N E^{E \prime}\right)\end{array}$ & $\mathrm{MWh} / \mathrm{y}$ & - & 1.40 & 2.58 & 8.83 & - & - & - & 12.8 \\
\hline
\end{tabular}

Table 4: Energy Analysis of System III

\begin{tabular}{|c|c|c|c|c|c|c|c|c|c|}
\hline & & Boiler & Chiller & Auxiliaries & Electric devices & Air post-heating & Space heating & DHW & Total \\
\hline $\begin{array}{c}\text { Primary energy } \\
\text { Consumption }\left(P E_{F u e l}\right)\end{array}$ & MWh/y & 26.6 & - & - & - & - & - & - & 26.6 \\
\hline $\begin{array}{c}\text { Thermal energy } \\
\text { production }\end{array}$ & MWh/y & 23.9 & - & - & - & - & - & - & 23.9 \\
\hline $\begin{array}{l}\text { Thermal energy } \\
\text { consumption }\end{array}$ & MWh/y & - & - & - & - & 1.41 & 6.51 & 16.0 & 23.9 \\
\hline $\begin{array}{c}\text { Electricity } \\
\text { consumption }\left(N E^{E I}\right)\end{array}$ & MWh/y & - & 3.10 & 1.55 & 8.83 & - & - & - & 13.5 \\
\hline
\end{tabular}

an overall efficiency of $82.1 \%$. As assumed, $50 \%$ of the net electricity consumption $\left(N E^{E l}=12.8 \mathrm{MWh} / \mathrm{y}\right)$ is taken from the grid $\left(D E^{E I}=6.40 \mathrm{MWh} / \mathrm{y}\right)$, and the remaining $50 \%(6.40 \mathrm{MWh} / \mathrm{y})$ is provided by the MCHP. Therefore exported electricity is equal to $X E^{E l}=14.3$ $\mathrm{MWh} / \mathrm{y}-6.40 \mathrm{MWh} / \mathrm{y}=7.90 \mathrm{MWh} / \mathrm{y}$, that is about $55 \%$ of the production.

Energy analysis of system II is reported in Table 3. The results are very similar to those of Table 2, but all thermal energy demand is provided by the boiler, as well as all electricity is fully taken from the external grid.

Energy analysis of system III is reported in Table 4. Also in this case, thermal energy and electricity are wholly supplied by the natural gas boiler and by the grid, respectively. Electric energy demand for chiller and auxiliaries is different from that of Tables $\mathbf{2}$ and $\mathbf{3}$, due to the bigger size of the vapour compression device and to the different layout of the AHU. Furthermore, thermal energy requirement for $\mathrm{DW}$ regeneration in Table $\mathbf{2}$ and $\mathbf{3}$ is now substituted by thermal energy demand for air post-heating, as the conventional AHU in system III is based on cooling dehumidification, not desiccant one.

In Figure 6, the TEWI for the three systems is shown, considering GWP of R407C equal to 1800 $\mathrm{kg}_{\mathrm{CO} 2} / \mathrm{kg}_{\mathrm{GHG}}$. As regards system I, the major contribu- tion is the indirect one from the MCHP (about $224 \mathrm{t}$ $\mathrm{CO}_{2}$ ), that is widely higher than the indirect amount related to the boiler (about $9 \mathrm{t} \mathrm{CO}_{2}$ ) and the direct amount of the chiller (less than $5 \mathrm{t} \mathrm{CO}_{2}$ ). TEWI reduction due to electricity exchanged with the grid ($17 \mathrm{t} \mathrm{CO}_{2}$ ) determines a net value of the assessment index of about $220 \mathrm{t} \mathrm{CO}_{2}$.

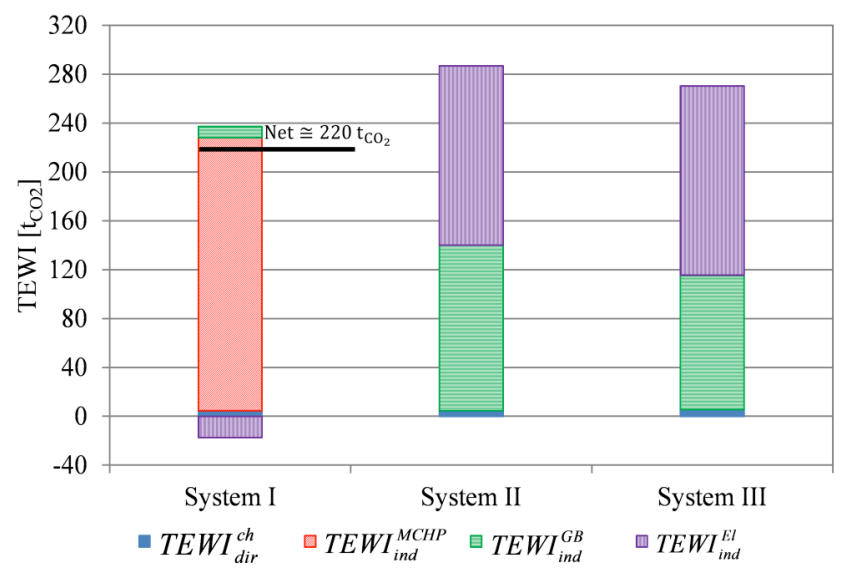

Figure 6: TEWI for the investigated systems (GWP $=1800$ $\mathrm{kgCO}_{\mathrm{C}} / \mathrm{kg}_{\mathrm{GHG}}$ ).

As regards system II, the direct contribution of the chiller is the same than in system I. The indirect contributions of natural gas boiler and electric grid are similar, 135 and $147 \mathrm{t} \mathrm{CO}_{2}$, respectively. 
As regards system III, there is a slightly increase of $T E W I_{d i r}^{c h}$ from 4.73 to $5.67 \mathrm{t} \mathrm{CO}_{2}$, due to the larger refrigerant charge in the chiller of this system. However, the direct contribution of the chiller is very low compared to the indirect ones, in fact the ratio between $T E W I_{d i r}^{c h}$ and the overall $T E W I$ is about $2 \%$ for all investigated systems.

As a final comparison, system I determines a reduction of TEWI of about $23 \%$ and $19 \%$ with respect to systems II and III, respectively. The overall TEWI $\left(271 \mathrm{t} \mathrm{CO}_{2}\right)$ of system III is lower than that of system II.

This analysis has been repeated to take into account the uncertainty about GWP values found in literature. If this parameter is assumed equal to 1525 $\mathrm{kg}_{\mathrm{CO} 2} / \mathrm{kg}_{\mathrm{GHG}}$, no significant changes appear, due to the low direct contribution of the chiller with respect to the overall TEWI. Therefore, in the following analyses, the value of $1800 \mathrm{~kg}_{\mathrm{CO} 2} / \mathrm{kg}_{\mathrm{GHG}}$ for the $G W P_{100}^{R 407 C}$ will be used.

A further analysis can be performed by calculating the TEWI index considering the direct and indirect contributions of the chiller only (Figure 7), as commonly done in literature. The former can be evaluated by Eq. 3 , while for the latter the following equation can be used:

$$
T E W I_{\text {ind }}^{c h}=\left[\frac{N E^{E L-c h} \cdot \gamma}{\eta_{E l}^{M C H P}}\left(1-\frac{\eta_{T h}^{M C H P}}{\eta^{G B}}\right) \cdot \beta+N E^{E L-c h} \cdot(1-\gamma) \alpha\right] \cdot V
$$

where $N E^{E L-c h}$ is the annual electricity consumption of the chiller, that can be derived from Tables $\mathbf{2}$ to $\mathbf{4}$ for the three analyzed systems. $y$ is the fraction of $N E^{E L-c h}$ supplied by the MCHP, equal to about $67.7 \%$ in system I and obviously to $0 \%$ in both systems II and III. $\eta_{E I}^{M C H P}$ and $\eta_{T h}^{M C H P}$ are the electric and thermal efficiency of the MCHP, equal to $26.5 \%$ and $55.6 \%$, respectively (Table 2 ); both values are very close to the rated ones. $\eta^{G B}$ is thermal efficiency of gas boiler that should be used to produce thermal energy that is provided by the MCHP while powering the chiller in System I $\left(\eta^{G B}=90.2 \%\right)$.

In this analysis, the direct contribution of the chiller is not negligible, in fact the ratio $T E W I_{d i r}^{c h}$ $/\left(T E W I_{d i r}^{c h}+T E W I_{\text {ind }}^{c h}\right)$ is about $29 \%, 23 \%$ and $14 \%$ for systems I, II and III, respectively. These results state that the greenhouse effect due to the refrigerant fluid contained in a vapour compression unit can be neglected when the environmental analysis is related to systems consisting of several energy conversion devices (MCHP, boiler, chiller), but it cannot be neglected when the analysis considers the vapour compression unit only.

The absolute values of TEWI related to the chiller are also shown in the upper part of Figure 7. Also in this case, the lowest environmental impact is associated to System I.

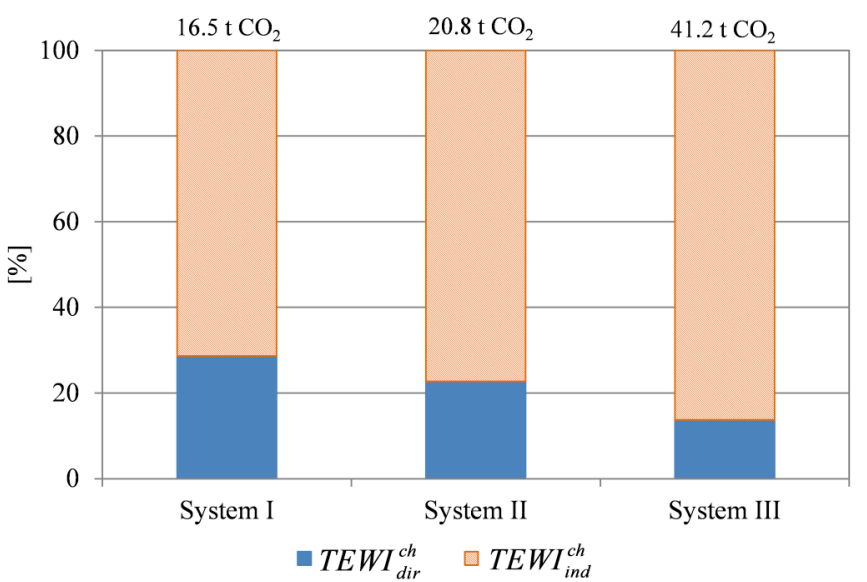

Figure 7: TEWI of the chiller for the investigated systems.

The indirect contribution of electricity drawn from or fed to the grid (Eq. 6) strongly depends on $\alpha$, the specific emission factor of electricity, that is a countryrelated parameter, as it depends on the electricity production mix of each region. To take into consideration this issue and to show how it affects the results, in Figure 8 the $\triangle T E W I$ is shown as a function of $\alpha$.

TEWI for system I reduces when $\alpha$ increases, as $T E W I_{\text {ind }}^{E l}$ is a negative amount $\left(D E^{E L}<X E^{E l}\right)$, while TEWI for systems II and III rises with $\alpha$. Due to that, $\triangle T E W I_{\text {I-II }}$ and $\triangle T E W I_{1-I I I}$ increase with the specific emission factor of electricity, achieving a maximum value of about $60 \%$ when $\alpha=1.2 \mathrm{~kg} \mathrm{CO}_{\mathrm{CO}} / \mathrm{kWh}_{\mathrm{EI}}$. Therefore, the environmental savings are very significant in countries, such as in Eastern Europe, strongly based on highly pollutant fossil fuels, e.g. coal, for electricity generation. On the contrary, when $\alpha$ is quite low, for example due to the strong contribution of nuclear power plants (France) or renewable technologies (Northern Europe countries) to electricity production, the environmental benefit of the hybrid DCS with MCHP is strongly negative, in comparison with both systems II and III. System I becomes feasible with respect to the other compared systems starting from values of $\alpha$ of about $0.400 \mathrm{kgCO} / \mathrm{kWh}_{\mathrm{El}}$.

As regards $\left.\triangle T E W\right|_{I I-I I}$, it is less sensitive to $\alpha$ with respect to the other comparison indices, as both systems II and III draw electricity from the grid. $\triangle T E W I_{|-| I I I}$ slightly increases with $\alpha$, but it never 


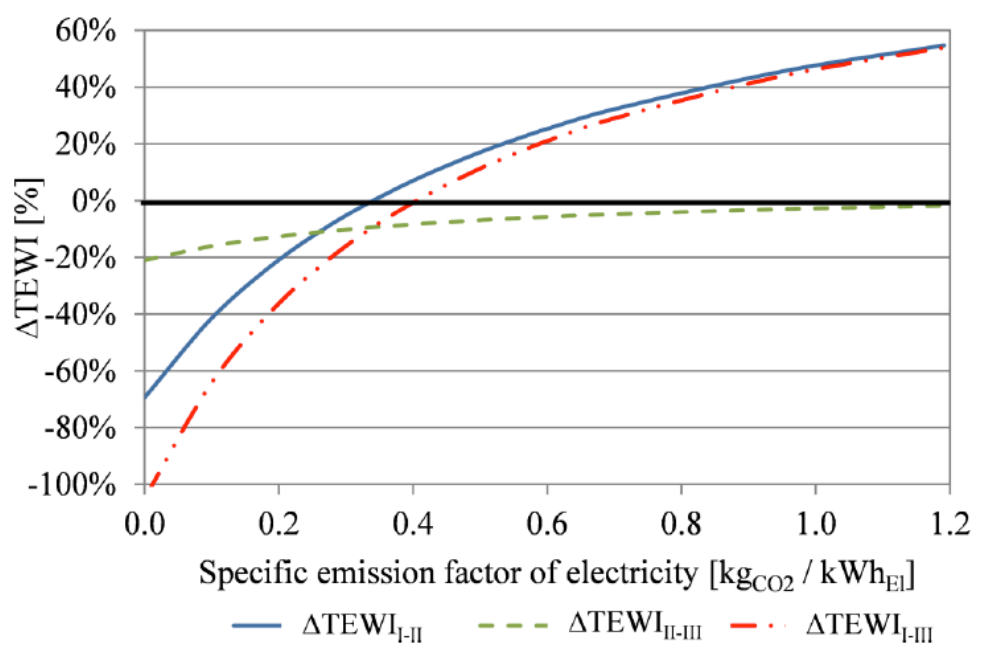

Figure 8: TEWI parameter as a function of specific emission factor of electricity.

becomes positive, therefore the hybrid DCS interacting with the boiler and the electric grid is never environmentally feasible, in any scenario of electricity production mix.

\section{CONCLUSIONS}

In this paper, the TEWI (Total Equivalent Warming Impact) method, that is usually applied to electricallydriven vapour compression cooling devices, is extended to a hybrid desiccant cooling system interacting with a microcogenerator, a boiler and an electric chiller (named system I). It provides the airconditioning service to a lecture room during summer and winter periods and thermal energy for domestic hot water production to a nearby multifamily house or to a generic thermal user (a sports center, a pool, a leisure complex, etc.)

This system is compared with the same desiccantbased cooling system without microcogenerator (system II), and with a conventional air handling unit, based on cooling dehumidification for summer air conditioning (system III). In both systems II and III, electricity is drawn from the grid and thermal energy is provided by a natural gas boiler. The energy and environmental analysis is performed for the three systems, considering the contributions of each device.

The results showed that system I determines a reduction of TEWI of about $23 \%$ and $19 \%$ with respect to systems II and III, respectively. Furthermore, the direct contribution of the chiller can be neglected as it is very low (about $2 \%$ ) compared to the overall TEWI. On the contrary the direct contribution of the chiller cannot be neglected when the emission analysis involves the vapour compression unit only.
The analysis for the overall system was conducted considering the minimum and maximum values of the GWP parameter found in literature, achieving practically the same results in terms of overall TEWI of the compared systems. This is due to the negligible contribution of the direct contribution from the chiller, therefore the uncertainty of the parameters involved in its calculation has no effect on the obtained results in terms of overall TEWI.

The effect on TEWI of the specific emission factor of electricity, that depends on electricity mix production, was also investigated. The results showed that the hybrid desiccant cooling system with microcogenerator is feasible when at least about $0.400 \mathrm{~kg}$ of $\mathrm{CO}_{2}$ are emitted for each $\mathrm{kWh}$ of electric energy drawn from the grid.

As a future development of this study, the TEWI for the investigated systems will be further extended to also involve the direct contribution of natural gas leakages in the distribution pipes that supply the fuel to on-site energy conversion devices, microcogenerator and boiler, and to centralized thermo-electric power plants.

\section{NOMENCLATURE}

DE electricity drawn from the grid, MWh/y

EER Energy Efficiency Ratio

GWP Global Warming Potential, $\mathrm{kg}_{\mathrm{CO} 2} / \mathrm{kg}_{\mathrm{GHG}}$

NE net energy, MWh/y

$\mathrm{PE} \quad$ primary energy, $\mathrm{MWh} / \mathrm{y}$ 


\begin{tabular}{|c|c|c|c|}
\hline \multirow[t]{2}{*}{$P_{L}$} & \multirow{2}{*}{$\begin{array}{l}\text { accidental refrigerant leaks per year ( } \% \\
\text { refrigerant charge/year) }\end{array}$} & \multicolumn{2}{|c|}{ Subscripts } \\
\hline & & 100 & integration time of 100 years \\
\hline$P_{R}$ & recycling rate ( $\%$ refrigerant charge) & $\mathrm{CO}_{2}$ & carbon dioxide \\
\hline $\mathrm{RC}$ & refrigerant charge, $\mathrm{kg}$ & $\operatorname{dir}$ & direct contribution \\
\hline TEWI & Total Equivalent Warming Impact $\left(\mathrm{kg} \mathrm{CO}_{2}\right)$ & $\mathrm{El}$ & electricity \\
\hline V & plant useful life, years & Fuel & fuel primary energy \\
\hline XE & exported electricity, MWh/y & GHG & greenhouse gas \\
\hline AHU & air handling unit & 1 & related to system I \\
\hline B & boiler & II & related to system II \\
\hline $\mathrm{CC}$ & cooling coil & III & related to system III \\
\hline CF & cross flow & ind & indirect contribution \\
\hline $\mathrm{CH}$ & chiller & PE & primary energy \\
\hline DCS & desiccant cooling system & Supers & ripts \\
\hline DHW & domestic hot water & $\mathrm{ch}$ & chiller \\
\hline DW & desiccant wheel & $\mathrm{El}$ & electricity \\
\hline EC & evaporative cooler & GB & gas boiler \\
\hline GHG & greenhouse gas & $\mathrm{MCHP}$ & micro combined heat and power \\
\hline $\mathrm{HC}$ & heating coil & R407C & R407C refrigerant fluid \\
\hline
\end{tabular}

HVAC heating ventilation and air conditioning

MCHP micro combined heat and power

MFH multifamily house

RS reference system

TS thermal storage

\section{Greek symbols}

[3] Baniyounes AM, Liu G, Rasul MG, Khan MMK. Analysis of solar desiccant cooling system for an institutional building in subtropical Queensland, Australia. Renew Sust Energ Rev 2012; 16: 6423-31.

$\alpha \quad$ specific emission factor of electricity, $\mathrm{kg}_{\mathrm{cO} 2} /$ $\mathrm{kWh}_{\mathrm{El}}$ http://dx.doi.org/10.1016/j.rser.2012.07.021

[4] Calise F, Dentice d'Accadia M, Roselli C, Sasso M, Tariello F. Desiccant-based AHU interacting with a CPVT collector: Simulation of energy and environmental performance. Sol Energy 2014; 103: 574-94. http://dx.doi.org/10.1016/j.solener.2013.11.001

$\gamma \quad$ fraction of $N E^{E L-c h}$ provided by the MCHP

[5] Lee SH, Lee WL. Site verification and modeling of desiccantbased system as an alternative to conventional airconditioning systems for wet markets. Energy 2013; 55 1076-83. http://dx.doi.org/10.1016/j.energy.2013.04.029

$\eta \quad$ efficiency

[6] Angrisani G, Minichiello F, Roselli C, Sasso M. Desiccant HVAC system driven by a micro-CHP: Experimental analysis. 
Energ Build 2010; 42: 2028-35.

http://dx.doi.org/10.1016/j.enbuild.2010.06.011

[7] Angrisani G, Minichiello F, Roselli C, Sasso M. Experimental investigation to optimise a desiccant HVAC system coupled to a small size cogenerator. Appl Therm Eng 2011; 31: 50612.

http://dx.doi.org/10.1016/j.applthermaleng.2010.10.006

[8] Angrisani G, Roselli C, Sasso M, Tariello F. Dynamic performance assessment of a micro-trigeneration system with a desiccant-based air handling unit in Southern Italy climatic conditions. Energ Convers Manage 2014; 80: 188201. http://dx.doi.org/10.1016/j.enconman.2014.01.028

[9] Angrisani G, Roselli C, Sasso M, Tariello F. Assessment of Energy, Environmental and Economic Performance of a Solar Desiccant Cooling System with Different Collector Types. Energies 2014; 7: 6741-64. http://dx.doi.org/10.3390/en7106741

[10] Angrisani G, Roselli C, Sasso M. Experimental assessment of the energy performance of a hybrid desiccant cooling system and comparison with other air-conditioning technologies. Appl Energ 2015; 138: 533-45. http://dx.doi.org/10.1016/j.apenergy.2014.10.065

[11] de Rossi F, Mastrullo R, Sasso M. R502 substitution: a global evaluation of the environmental impact. In: IIR Paris, France, editor. Proceedings of the International Conference on Energy Efficiency in Refrigeration and Global Warming Impact, Commission B1/2 I.I.R. Ghent, Belgium 1993; pp. 335-9.
[12]

de Rossi F, Sasso M. An environmental and thermodynamic analysis to select R22 alternative working fluids. Int J Ambient Energy 1995; 16: 76-82. http://dx.doi.org/10.1080/01430750.1995.9675672

[13] Aprea C, Greco A, Maiorino A. The application of a desiccant wheel to increase the energetic performances of a transcritical cycle. Energ Convers Manage 2015; 89: 222230.

http://dx.doi.org/10.1016/j.enconman.2014.09.066

[14] Technical documentation of chillers from HVAC company RC Group, http://www.rcgroup.it/EN/. (accessed January 05, 2015).

[15] Aprea C, Greco A, Maiorino A. An experimental evaluation of the greenhouse effect in the substitution of $\mathrm{R} 134 \mathrm{a}$ with $\mathrm{CO}_{2}$. Energy 2012; 45: 753-761. http://dx.doi.org/10.1016/j.energy.2012.07.015

[16] Benhadid-Dib S, Benzaoui A. Refrigerants and their environmental impact. Substitution of hydro chlorofluorocarbon HCFC and HFC hydro fluorocarbon. Search for an adequate refrigerant. Energy Procedia 2012; 18: 807-16.

http://dx.doi.org/10.1016/j.egypro.2012.05.096

[17] Aghahosseini S, Dincer I. Comparative performance analysis of low-temperature Organic Rankine Cycle (ORC) using pure and zeotropic working fluids. Appl Therm Eng 2013; 54: 3542.

http://dx.doi.org/10.1016/j.applthermaleng.2013.01.028

Received on 15-01-2015

Accepted on 02-02-2015

Published on 01-04-2015

DOI: http://dx.doi.org/10.15377/2409-5818.2014.02.01.2

(C) 2014 Angrisani et al.; Avanti Publishers.

This is an open access article licensed under the terms of the Creative Commons Attribution Non-Commercial License (http://creativecommons.org/licenses/by-nc/3.0/) which permits unrestricted, non-commercial use, distribution and reproduction in any medium, provided the work is properly cited. 